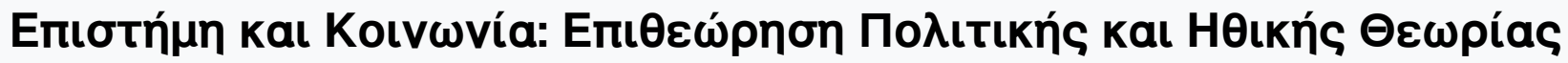

Tóp. 1 (1998)

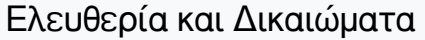

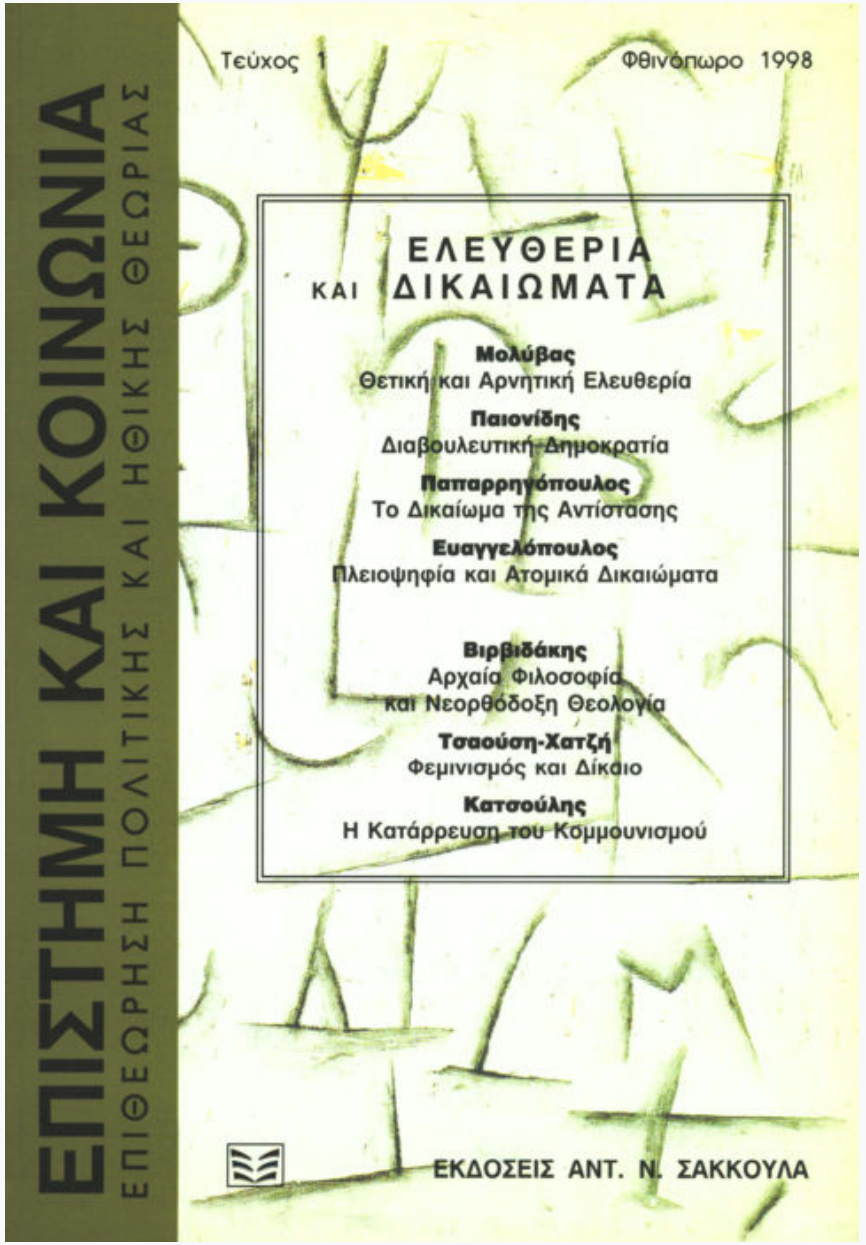

\section{F. Rosen, Bentham, Byron, and Greece: \\ Constitutionalism, Nationalism, and Early Liberal Political Thought}

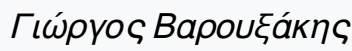

doi: $10.12681 /$ sas.690

Copyright @ 2015, Гı́́pүoc Bapouそáknc

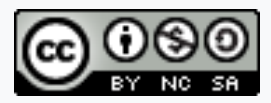

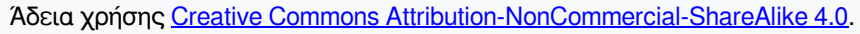

\section{Bıß入ıоррачıкń avaџopá:}

Bapoukáknৎ Г. (2015). F. Rosen, Bentham, Byron, and Greece: Constitutionalism, Nationalism, and Early Liberal

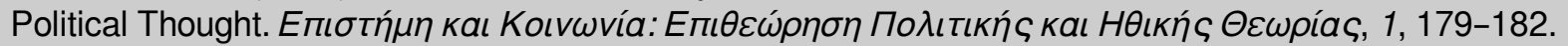

https://doi.org/10.12681/sas.690 


\section{F. Rosen, Bentham, Byron, and Greece: Constitutionalism, Nationalism, and Early Liberal Political Thought, Oxford: Clarendon Press, 1992}

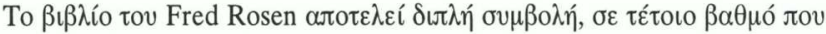
$\theta \alpha \mu \tau$

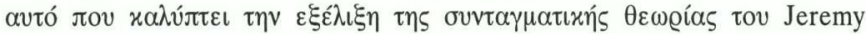
Bentham a

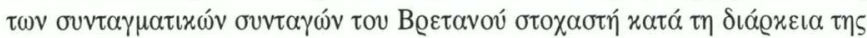

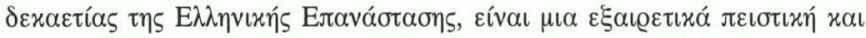

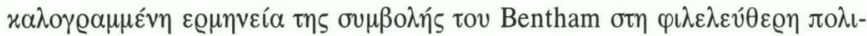

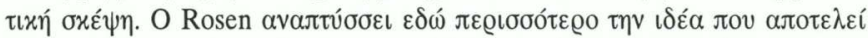

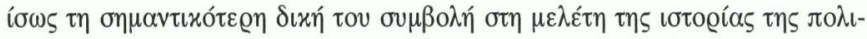

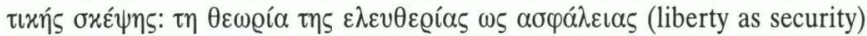

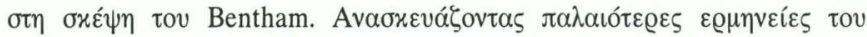

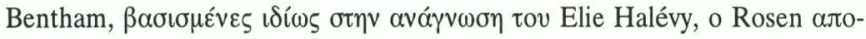

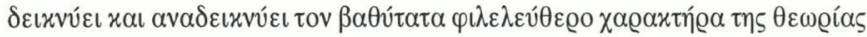

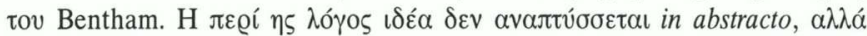

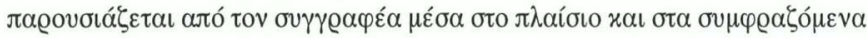

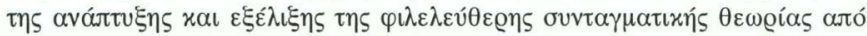

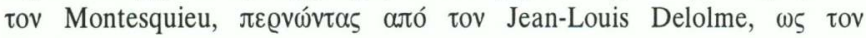
Blackstone.

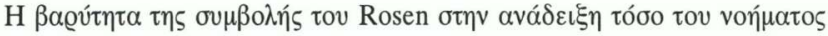

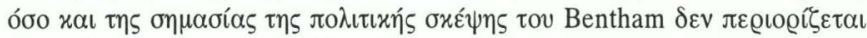

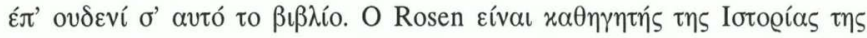

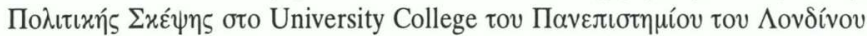

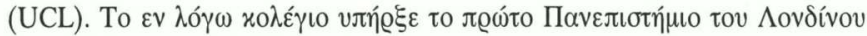

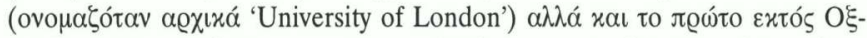

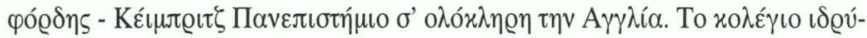

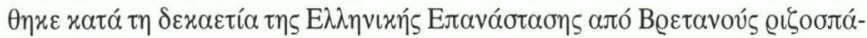

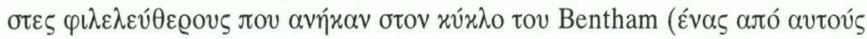




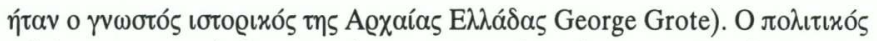

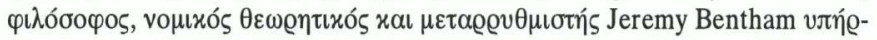

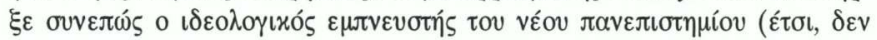

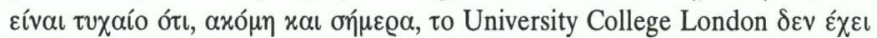

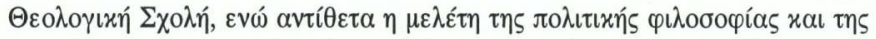

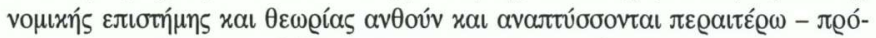

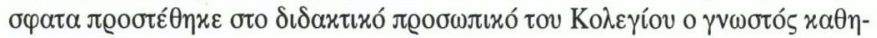

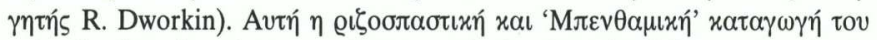

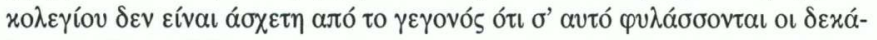

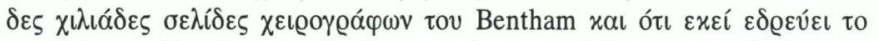

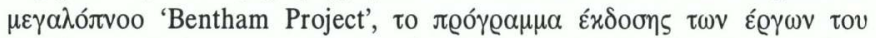

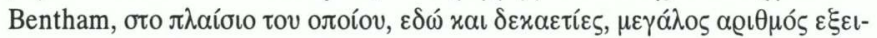

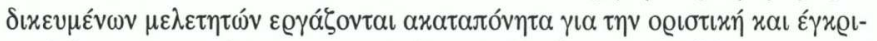

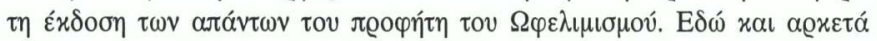

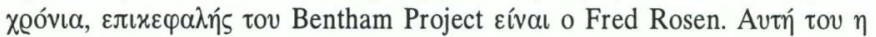

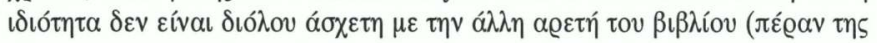

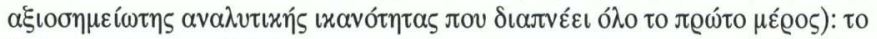

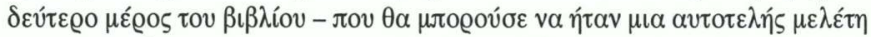

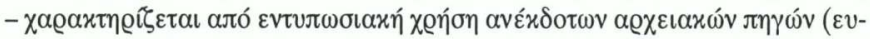

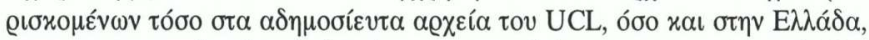

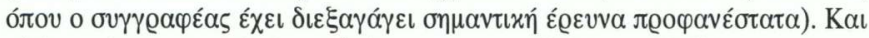

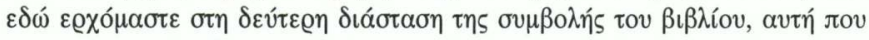

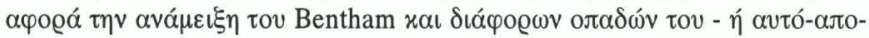

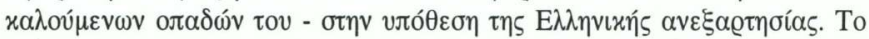

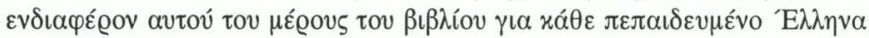

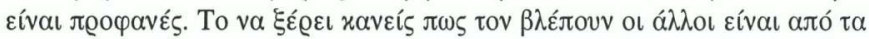

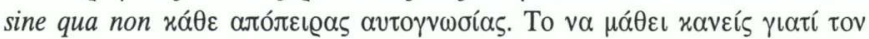

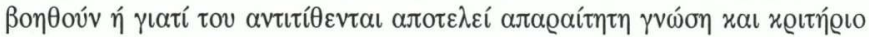

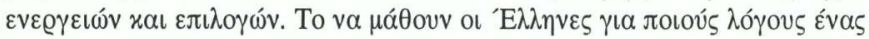

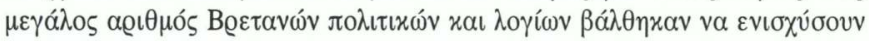

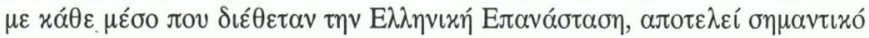

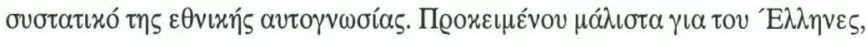

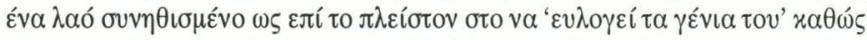

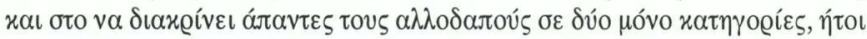

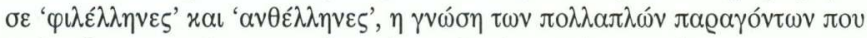

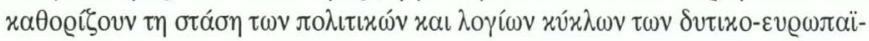

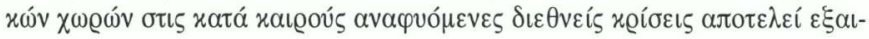




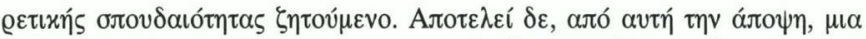

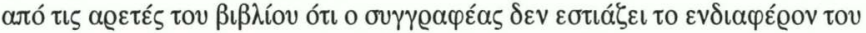

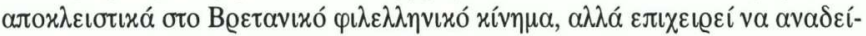

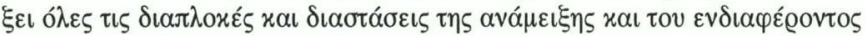

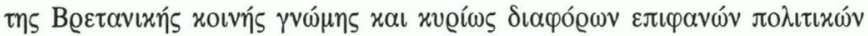

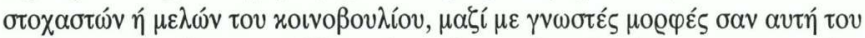

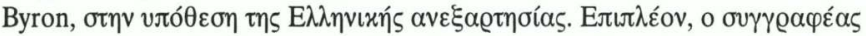

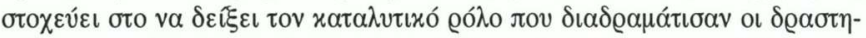

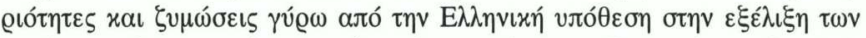

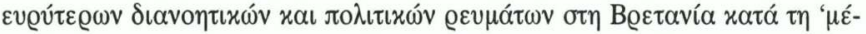

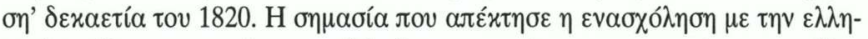

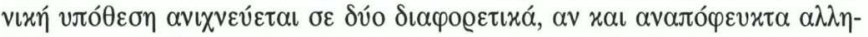

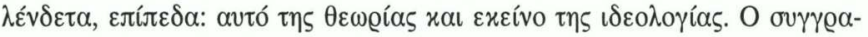

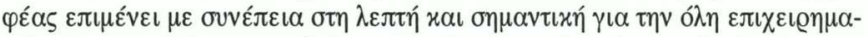

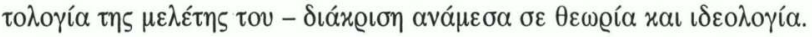

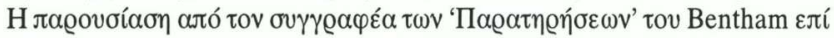

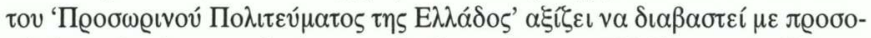

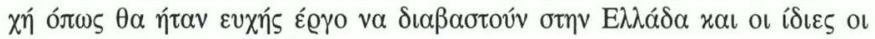

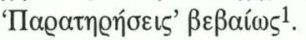

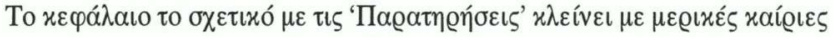

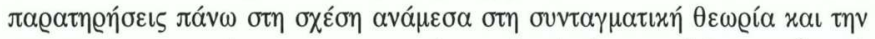

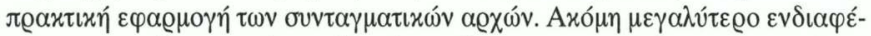

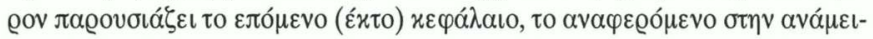

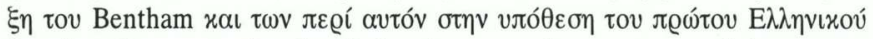

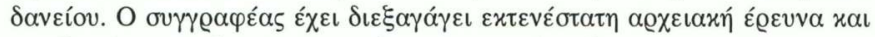

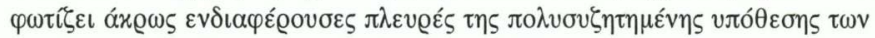

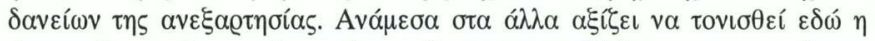

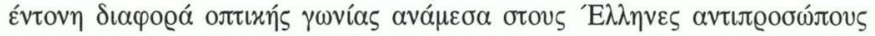

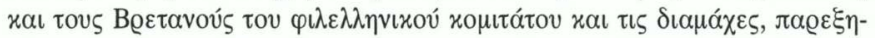

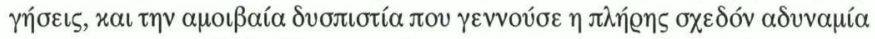

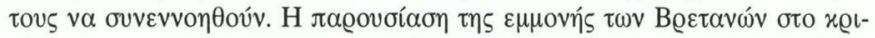

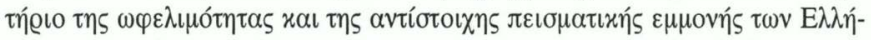

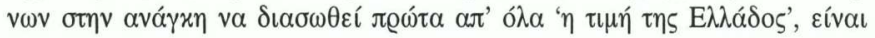

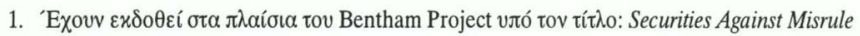

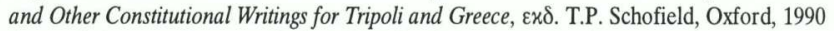

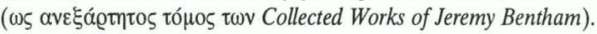




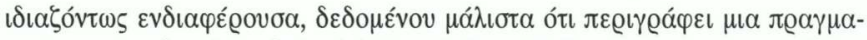

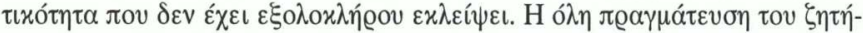

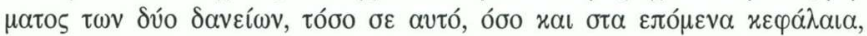

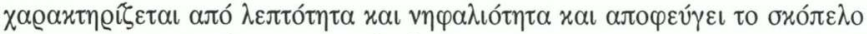

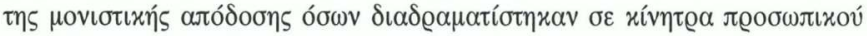

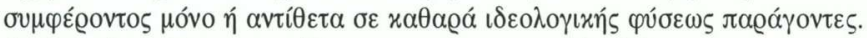

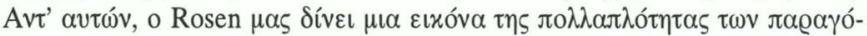

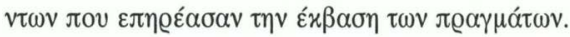

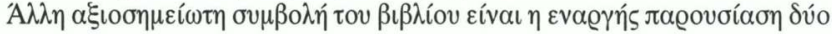

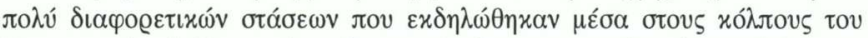

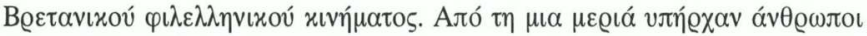

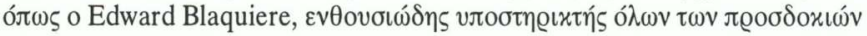

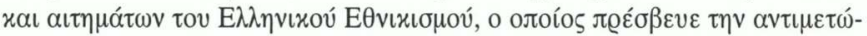

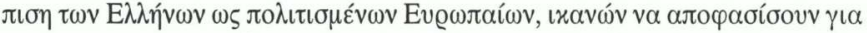

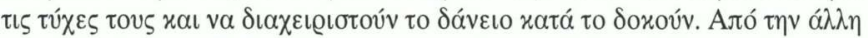

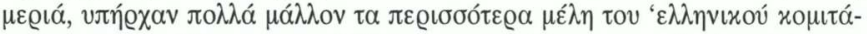

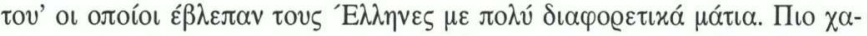

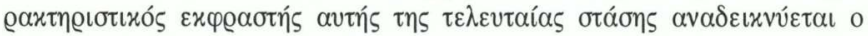

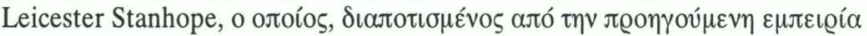

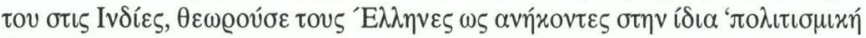

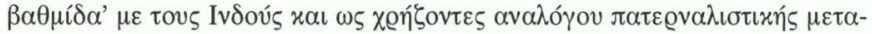

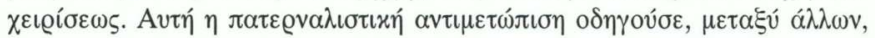

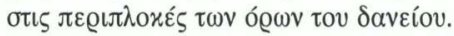

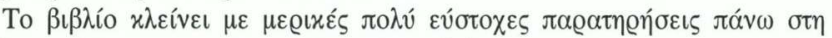

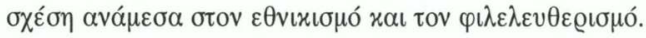

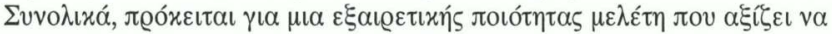

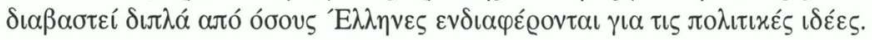

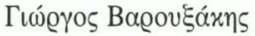

